\title{
EFFECTIVENESS OF SUGAR SORGHUM HYBRIDS IN THE ARID CONDITIONS OF NORTH CAUCASUS
}

\author{
Sergey Ivanovich Kapustin ${ }^{1}$, Alexander Borisovich Volodin ${ }^{1}$, Angelina Sergeevna Kapustina ${ }^{2}$, \\ Andrey Sergeevich Kapustin ${ }^{3 *}$ \\ ${ }^{I}$ North Caucasus Federal Agricultural Research Center, Nikonov str. 49, Mikhailovsk, \\ Stavropol region, 356241, Russia; \\ ${ }^{2}$ Stavropol State Medical University, Mira str. 310, Stavropol, 355017, Russia; \\ 3*North Caucasus Federal University, Pushkin str. 1, Stavropol, 355017, Russia; \\ *Corresponding Author Andrey Sergeevich Kapustin, e-mail: hpplus@bk.ru;
}

Received May 2020; Accepted June 2020; Published July 2020;

DOI: https://doi.org/10.31407/ijees10.301

\begin{abstract}
The aim of the research is to clarify in arid conditions the morphological and yield indicators of new varieties and hybrids of sugar sorghum, their combination with the sugar content in the juice of the stems. In 5 new Moldavian hybrids and 3 Stavropol standards of different ripeness groups, the maximum seedling period - seed maturation (154 days) was fixed for the Sasm-1 variant. The intensity of the initial plant growth on the 30th day of vegetation was most significant in the Yarik standard $(61.5 \mathrm{~cm})$ and the $5 a s m-1$ variant $(59.5 \mathrm{~cm})$. The same indices obtained the highest indices of plant height $(275.0 \mathrm{~cm}$ and $272.5 \mathrm{~cm})$ and stem diameter $(2.15 \mathrm{~cm}$ each). The stem core has a semi-juicy consistency. On average for 2018-2019, the most significant green mass yield and stalk productivity were also obtained from the Moldovan sample Sasm-1 (respectively $81.1 \mathrm{t} / \mathrm{ha}$ and $62.0 \mathrm{t} / \mathrm{ha}$ ) and the Yarik standard ( $84.2 \mathrm{t} / \mathrm{ha}$ and $63.8 \mathrm{t} / \mathrm{ha}$ ). By the sugar content in the juice of the stems, the majority of Moldovan forms had an advantage over the standards. The maximum sugar content was found in Euralis Es Athena + S4 (Concept III) 20.9\% and BMR Gold + S4 (Concept III) - 20.1\%. In the hybrids Sasm-1 and Sasm-2, this indicator varied between $18.4 \%$ and $19.2 \%$, which is also higher than the standards (14.1-18.5\%). The highest sugar yield per hectare was obtained for the Moldovan variant of Sasm-1 - 3.42 t/ ha, which is $0.21 \mathrm{t} /$ ha higher than the medium-late hybrid Yarik. The rest of the studied samples reduced the sugar yield to $1.89-2.75 \mathrm{t} / \mathrm{ha}$.
\end{abstract}

Key words: sugar sorghum, hybrid, selection, green mass productivity, sugar content and yield. 